\title{
The Effectiveness of Self-directed Learning Ability Improvement Program for College Students on Academic Probation
}

\section{대학생 학사경고자를 위한 자기주도학습능력 증진 프로그램의 효과 연구}

Youngran Yoon ${ }^{1}$

윤영란1

${ }^{1}$ Professor, College of Liberal Arts, Seokyeong University, Korea, yoon1112@skuniv.ac.kr

\begin{abstract}
The purpose of this study is to analyze self-directed learning ability improvement program by analyzing the causes of academic warning and verifying its effectiveness. Through the analysis of the causes of academic warnings, the components of the self-directed learning ability improvement program for academic warnings were derived. As a result, a total of five program sessions were conducted to determine the five activity areas related to the learning strategy and to verify the effectiveness of the program. The participants of the program were 18 college students who received an academic warning in the previous semester, and the effectiveness of the program was verified by a selfdirected learning ability test. The results of the study are as follows. First, the results of the analysis of the causes of academic warning factors are ineffective learning methods, lack of learning and will, difficulty in majoring, psychological and emotional problems, employment and employment at other universities, family form, and health problems. The most difficult parts of university study were lack of learning strategy, time management, group class and discussion, note taking, basics of major, and report writing. Second, the self-directed learning ability of students who participated in the self-directed learning ability improvement program for college students on academic problem were generally improved. It can be said that learners have the ability to voluntarily lead the overall academic process from learning planning, learning execution, and learning evaluation. Based on the results of these studies, specific suggestions were made for university students who have received academic warnings.
\end{abstract}

Keywords: College Students, Academic Probation, Academic Warning Cause Analysis, Self-directed Learning Ability Improvement Program, Self-directed Learning Ability Test

요약: 본 연구의 목적은 학사경고자 원인 분석을 통한 자기주도학습능력 증진 프로그램을 운 영하고 그 효과성을 검증하고자 한다. 이를 위해 먼저 학사경고 원인 분석을 통해 학사경고자 를 위한 자기주도학습능력 증진 프로그램의 구성요소를 도출하였다. 그 결과 학습전략 관련 5 개의 활동영역을 확정하고 학사경고자 대상 자기주도학습능력 프로그램의 효과를 검증하기 위해 총 5 회기의 프로그램을 진행하였다. 프로그램에 참여한 학생은 직전 학기 학사경고를 받 은 대학생 18 명이며 프로그램의 효과성 검증은 자기주도적 학습능력 검사로 하였다. 연구의 결과는 다음과 같다. 첫째, 학사경고원인 분석 결과, 비효과적 학습 방법, 학습 동기 및 의지

Received: March 22, 2021; 1st Review Result: May 07, 2021; 2nd Review Result: June 22, 2021

Accepted: July 31, 2021 
부족, 전공 이수 어려움, 심리 및 정서적 문제, 다른 대학 입시 준비 및 취업, 가정형편, 건강 문제 순으로 나타났다. 대학학습에 가장 어려움을 느끼는 부분으로는 학습전략 부족, 시간 관 리, 조별 수업 및 토론, 노트 필기, 전공기초, 보고서 작성 순으로 나타났다. 둘째, 대학생 학사 경고자를 위한 자기주도학습능력 증진 프로그램에 참여한 학사경고자 학생들의 자기주도학습 능력이 전반적으로 향상되었다. 자기주도적으로 학습에 대한 계획을 세우고, 학습을 실행하며, 학습을 평가하는 전반적인 학업에 대한 과정을 학습자가 자발적으로 이끌어갈 수 있는 역량 을 강화했다고 할 수 있다. 이러한 연구 결과를 중심으로 대학에서 학사경고자를 위한 학습지 원 관련한 구체적인 제언을 하였다.

핵심어: 대학생, 학사경고, 학사경고원인분석, 자기주도학습능력 증진 프로그램, 자기주도 학습능력 검사

\section{1. 서론}

대학은 사회의 인재를 양성하는 곳으로 매우 중요한 국가적 책무를 수행하는 곳이다. 최근에는 학력 인구의 감소와 청년실업 문제가 심각해지면서 대학도 잘 가르치기 위한 교육역량을 높여 자체적으로 경쟁력을 갖추기 위해서 많은 노력을 기울이고 있다.

대학생에게도 대학 시기는 매우 중요한 시기인데 새로운 방향으로의 전환이 진행되는 시점으로 여러 가지 다양한 문제들을 능동적으로 해결해 나갈 수 있는 지식과 역량을 키 워야 하는 시기이다. 성공적인 대학학습을 위해서는 자기주도적인 학습능력은 매우 중요 한 능력인데 우리나라 대학생들은 고등학교 때까지 이어온 수동적인 학습습관이나 학습 태도로 인하여 자기주도적인 적절한 적응능력과 대처능력이 부족한 것이 사실이다[1].

자기주도적인 학습이란 학습자가 학습에 대한 주도권을 가지고, 학습 욕구를 진단하여 학습 목표를 설정하며, 학습에 필요한 인적. 물적 자원을 확보하고, 적합한 학습전략을 선택 ·실행하며 자신이 성취한 학습 결과를 스스로 평가하는 과정을 포괄한다[2].

학습에서의 주도성이 낮은 수동적 학습자들은 결국 대학학습에 적응하지 못하고 학사 경고나 학업 부진으로 이어지게 된다. 이에 각 대학에서는 학사경고자에 대한 체계적인 관리와 다양한 학습지원을 통하여 학사경고자가 발생하지 않도록 많은 노력을 기울이고 있으나 학사경고를 받는 학생들은 해마다 증가하고 있다.

학사경고는 학업 부진과 중도탈락과 직접적으로 연계되어 있어서 사후관리보다는 예방 이나 지원의 차원에서 접근하는 것이 바람직하다[3]. 대부분의 학사경고 제도는 경고 내 지 징벌의 관점으로 이해하고 있어 최소한의 학업성취 기준을 달성하여 성공적인 대학 생활을 지원하기에는 많이 부족하다[4].

따라서 학사경고자에 대한 학업적인 지원은 학사경고 제도의 본래 취지에 맞게 최소한 의 학업성취 기준을 설정하여 학생들이 그 기준을 성취하도록 독려하고, 기준에 부합하 지 못한 경우 학업 부진을 극복하도록 돕기 위한 것이어야 한다[5].

학사경고는 학업을 독려하고 학사경고를 극복할 수 있도록 다각적인 방법으로 도움을 주어야 하는데 학사경고 발생 원인이 다양하므로 학사경고자를 위한 프로그램도 학사경 고 발생원임을 분석하여 그 내용으로 프로그램을 운영할 필요가 있다[6].

따라서 본 연구에서는 학사경고자가 주도적으로 학사경고를 탈출하고 성공적인 대학학 습에 임할 수 있도록 학사경고자 원인 분석을 통한 자기주도학습능력 증진 프로그램을 
운영하고 그 효과성을 검증하고자 한다.

\section{2. 이론적 배경}

\section{1 대학의 학사경고제도}

학사경고제도란 성공적인 대학학습을 위해 최소한의 학업 성취 기준을 정하여 이 기준 을 충족시키지 못한 경우 일련의 제재를 가하는 제도이다. 대학마다 학사경고를 주는 학 업 성취 기준을 학점으로 정하고 있으며 학기 평점이 4.5점 만점인 경우에 보통 1.5 2.0 사이로 보고 있다. 우리 대학의 경우는 학기 평점 4.5점 만점에 1.6점 이하를 학사경고로 규정하고 있다. 학사경고 횟수가 누적되면 정학, 퇴학 등 행정적인 제재를 받게 된다.

학사경고 제도는 원래 최소한의 학업성취 기준을 설정하여 학생들로 하여금 최저 학업 성취 기준을 성취하도록 독려하고, 그 기준에 부합하지 못한 경우 학업적인 지원을 통해 학사경고를 극복하도록 돕기 위한 것이다. 학사경고는 학업부진 및 중도탈락의 문제뿐만 아니라 대학 생활부적응 측면에서 보면, 개인적으로나 사회적으로도 커다란 손실이라고 볼 수 있기 때문이다. 그러나 대학에서의 실제로 운영되고 있는 학사경고제도는 학업성 취를 충족하지 못한 학생들에게 대한 학업적인 지원보다는 제재를 가하는 일련의 징벌적 인 관점으로 운영되고 있다.

대학학습에서 최소한의 학업 성취 기준을 충족하기 위해서는 무엇보다 자기주도적인 학습능력이 필요한데 자기주도적 학습능력이란 학습자가 학습에 대한 주도권을 가지고, 학습욕구를 진단하여 학습목표를 설정하며, 학습에 필요한 인적. 물적 자원을 확보하고, 적합한 학습전략을 선택 실행하며 자신이 성취한 학습결과를 스스로 평가하는 과정을 포괄한다.

따라서 대학에서는 학사경고제도를 통해 일련의 제재를 가하기보다는 학사경고자를 위 한 학습적인 지원을 해야 하며 학사경고자 발생을 줄이기 위한 노력과 학사경고자가 발 생하지 않도록 자기주도적인 학습능력을 향상하기 위한 노력 등 다양한 노력을 해야 한 다.

\section{2 학사경고 관련 선행연구 분석}

학사경고와 관련한 선행연구는 다음의 세 가지 영역으로 구분된다.

첫째는 학사경고 원인분석이나 학사경고자의 특성 분석과 관련된 연구이다. 이를 통해 밝혀진 연구 결과들을 살펴보면, 학사경고의 원인은 낮은 학습 동기, 대학과 전공 불일 치, 대학과 전공에 대한 실망감, 스트레스 관리실패, 낮은 학업적 자기효능감, 대인관계 문제, 대학학습 방법의 어려움, 시간 관리 실패 등으로 나타났다[5-9]. 학사경고자의 특성 분석으로 밝혀진 공통된 특징은 낮은 학습동기였다. 학습동기는 기대되는 미래목표와 가 치를 위해 방향성과 목적을 가진 행동을 시작하게 하고 지속하는 힘으로 정의된다. 따라 서 학사경고자를 위한 개입 활동 중 가장 효과적인 지원은 자기주도적으로 자신의 삶의 목표를 설정하고 학습에 대한 구체적인 목표를 설정하여 스스로 학습할 수 있는 능동적 인 학습능력을 갖추는 것이라 할 수 있다.

대학생들이 자기 삶의 목표를 설정하고, 설정된 목표를 향해 학업에 집중하는 행동은 성공적인 학업을 위해서는 매우 필요한 과정이다. 학사경고는 학사경고자의 학습적인 문 
제로 발생하기도 하지만 개개인의 다양한 문제들로부터 발생한다. 가정적인 문제, 심리적 인 문제, 건강문제, 환경적인 문제 등등 개인적인 문제가 깊숙이 관여되어 있다. 따라서 학사경고를 탈출하고 성공적인 대학학습을 해나가도록 돕기 위해서는 학사경고자들이 어 떤 도움을 원하는지에 대한 학사경고자 의견수렴을 위한 사전요구조사와 학사경고자 발 생 원인에 대한 깊이 있는 조사가 이루어져야 한다.

둘째는 학사경고자 대상의 프로그램 개발 및 효과성 연구이다. 학사경고자 대상 자기주 도학습력 프로그램, 학습동기 향상 프로그램, 학습력 증진 프로그램. 스트레스 대처전략 프로그램, 시간 관리 프로그램, 학습전략 프로그램 등을 개발하고 프로그램의 효과성을 분석하고자 한 연구이다. 학사경고자 프로그램의 효과성 연구 결과는 대부분이 학습동기, 자기효능감 등에서 유의미한 향상을 보고하고 있다[10][11].

셋째는 학사경고자의 학사경고 극복과정에 대한 현상학적 연구들이다. 학사경고를 어떻 게 극복하였는지에 대한 심층 인터뷰와 자기 보고식 설문지 법 또는 사례분석의 질적 연 구이다[12]. 학사경고자가 학사경고를 어떻게 극복하였으며 학사경고를 탈출하는 데 가장 큰 도움을 받은 것이 무엇인지에 관한 인터뷰 중심의 현상학적 연구이다. 이를 통해 밝 혀낸 학사경고 극복 요인은 외부자극에 대한 동기부여가 가장 중요한 요인이었다. 성별 에 따라 동기부여 요인이 다르게 나타났는데 남학생은 목표수립 및 책임감이 중요한 요 인이었고 여학생은 심리적 안정감이 중요한 요인이었다[10-12].

이들 연구를 종합해볼 때, 학사경고자의 공통된 특징은 낮은 학습동기임을 알 수 있다. 학사경고를 극복하면서 가장 중요한 요인은 학습동기부여로 나타났다.

선행연구 결과, 학사경고 관련 연구는 학사경고자에 대한 사후 조치와 관련된 연구가 대부분이다. 특히 대학평가의 평가지표에 학사경고자에 대한 조치가 포함되면서 각 대학 에서는 학사경고자를 위한 다양한 관리방안 등을 제시하고 있으며 학사경고자 사후 관리 방안을 마련하기 위한 프로그램의 개발 및 운영에 관한 연구를 통해 학사경고자에 대한 관리방안을 제시하고 있는 것으로 나타났다.

\section{3. 연구대상 및 연구방법}

\section{1 연구대상}

본 연구를 위해 서울 소재 $\mathrm{S}$ 대학에서 학사경고를 받은 학생 78 명에 대한 학사경고 원 인 조사를 실시하였고 이 중 18 명이 교수학습지원센터에서 운영하는 학사경고자 학습지 원 프로그램에 참여하였다. 먼저 학사경고 원인 분석을 통해 학사경고자를 위한 자기주 도학습능력 증진 프로그램의 구성요소를 도출하였다. 자기주도학습을 위한 동기부여, 시 간 관리, 노트필기, 보고서 작성, 암기와 기억하기 등의 학습전략을 통해 대학학습에 도 움을 줄 수 있는 내용으로 영역을 구분하여 구성하였다.

본 연구의 진행 과정은 다음의 [그림 1]과 같다.

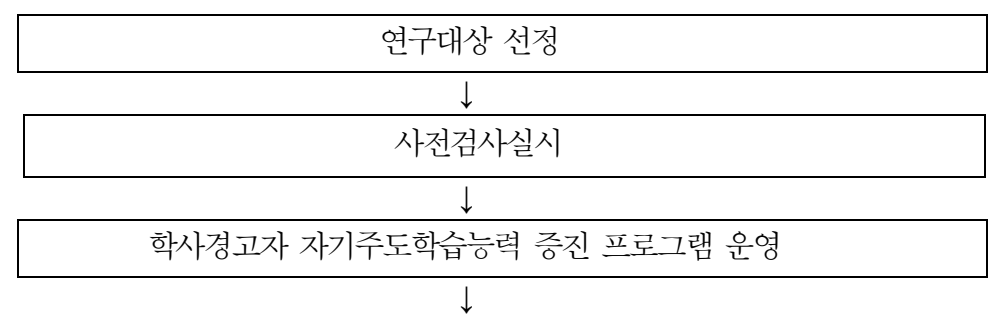




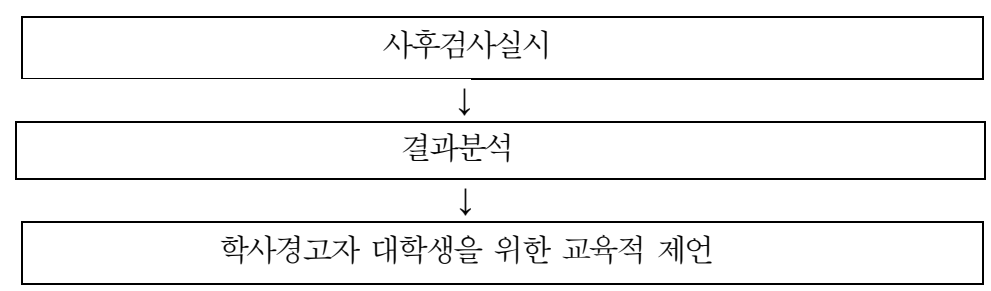

[그림 1] 연구 진행 과정

[Fig. 1] Research Process

\section{2 연구방법}

본 연구의 학사경고 원인분석은 기술통계 방법을 사용하였으며 프로그램의 효과성 분 석은 SPSS 21.0 프로그램을 활용하였으며 수집된 자료의 신뢰도 분석을 하였다. 학사경 고자를 위한 자기주도학습능력 증진 프로그램의 효과성을 측정하기 위해 이석재, 장유경, 이현남, 박광엽(2003)이 개발한 대학생(성인용) 자기주도적 학습능력 척도를 사용하였다 [13]. 자기주도적 학습 능력은 학습계획과 학습실행, 학습평가의 3 영역으로 구분되어 있으 며 학습계획은 하위요소인 학습욕구, 목표설정, 학습자원파악으로 구성되어 있다. 학습실 행의 하위요소는 자기관리능력, 학습전략, 학습실행지속이다. 학습평가는 결과에 대한 귀 인, 자기성찰의 하위요소로 구성되어 있다. 학습욕구 10 문항, 목표설정 5문항, 학습자원 파악 5 문항, 자기관리능력 5 문항, 학습전략 5 문항, 학습실행의 지속성 5 문항, 결과에 대한 노력귀인 5 문항, 자기성찰 5 문항 등으로 총 45 문항으로 구성된다. 각 문항은 Likert 5점 척 도를 사용하였고 점수가 높을수록 자기주도 학습능력이 높은 것을 의미한다. Cronbach's $\alpha$ 값은 학습계획 .76, 학습실행 .69, 학습평가 .80이었다.

\section{4. 연구결과 분석}

\section{1 학사경고원인 분석 결과}

본 연구를 위해 서울 소재 $\mathrm{S}$ 대학에서 학사경고를 받은 학생 78 명에 대한 학사경고 원인 조사를 실시하였다. 학사경고 원인 분석 결과, 학사경고를 받은 근본적인 원인으로 는 비효과적 학습 방법(28.21\%), 학습 동기 및 의지 부족(26.92\%), 전공 이수 어려움 (20.51\%), 심리 및 정서적 문제 $(8.97 \%)$, 다른 대학 입시 준비 및 취업 $(6.41 \%)$, 가정형편 $(6.41 \%)$, 건강 문제 $(2.56 \%)$ 순으로 나타났다.

대학에서 이루어지는 대부분의 학습은 자율성을 기반으로 한 자기주도학습으로 이루어 진다. 학습의 주도성을 가지고 스스로 학습목표를 설정하고 계획을 수립한 뒤 실행해 나 가면서 부딪히는 소소한 문제들을 극복하는 능력이 학업성취에 직접적인 영향을 미친다 즉 학생들 스스로가 자신의 학습에 대한 목표를 세우고 목표를 달성하기 위한 자기주도 적인 학습능력이 무엇보다 중요하다. 그러나 학사경고자 학생들은 대학에 입학해서 대학 학습에 필요한 학습방법에 대해 충분히 익히지 못한 채 대학학습에 임하고 있으며 이러 한 자기주도적인 학습능력의 부족은 대학학습에 어려움을 주는 것으로 볼 수 있다. 
[표 1] 학사경고를 받은 근본적인 원인

[Table 1] The Results of the Analysis of the Causes of Academic Warning Factors

\begin{tabular}{c|c|c|c|c|c|c|c|c}
\hline 항목 & $\begin{array}{c}\text { 타대학 } \\
\text { 입시준비 / } \\
\text { 취업 }\end{array}$ & $\begin{array}{c}\text { 전공이수 } \\
\text { 어려움 }\end{array}$ & $\begin{array}{c}\text { 학습동기 / } \\
\text { 의지 부족 }\end{array}$ & $\begin{array}{c}\text { 비효과적 } \\
\text { 학습방법 }\end{array}$ & $\begin{array}{c}\text { 심리. } \\
\text { 정서적 } \\
\text { 문제 }\end{array}$ & $\begin{array}{c}\text { 건강 } \\
\text { 문제 }\end{array}$ & $\begin{array}{c}\text { 가정 } \\
\text { 형편 }\end{array}$ & 합계 \\
\hline 빈도(\%) & $5(6.41 \%)$ & $16(20.51 \%)$ & $21(26.92 \%)$ & $22(28.21 \%)$ & $7(8.97 \%)$ & $2(2.56 \%)$ & $5(6.41 \%)$ & $78(100 \%)$ \\
\hline
\end{tabular}

대학학습에 가장 어려움을 느끼는 부분으로는 학습전략 부족 $(28.21 \%)$, 시간 관리 (21.79\%), 조별 수업 및 토론(17.95\%), 노트 필기(12.82\%), 전공기초(11.54\%), 보고서 작성 (7.69\%) 순으로 나타났다. 대학생들은 대학학습에 필요한 학습 전략적인 부분이 부족하고 자신의 시간을 주도적으로 관리하는 능력이 부족한 것으로 볼 수 있다. 대학학습은 자율 성을 기반으로 하고 있기 때문에 자기관리 능력의 부족은 대학학습에 많은 어려움을 준 다고 할 수 있다.

[표 2] 대학학습에 가장 어려움을 느끼는 부분

[Table 2] The Results of the Analysis of the Academic Difficulting Factors

\begin{tabular}{c|c|c|c|c|c|c|c}
\hline 항목 & 전공기초 & 노트 필기 & $\begin{array}{c}\text { 조별 수업 } \\
\text { 및 토론 }\end{array}$ & 시간 관리 & $\begin{array}{c}\text { 학습전략 } \\
\text { 부족(미흡 })\end{array}$ & 보고서 작성 & 합계 \\
\hline 빈도(\%) & $9(11.54 \%)$ & $10(10 \%)$ & $14(17.95 \%)$ & $17(21.79 \%)$ & $22(28.21 \%)$ & $6(7.69 \%)$ & $78(100 \%)$ \\
\hline
\end{tabular}

\section{2 학사경고자 대상 자기주도학습능력 증진 프로그램의 내용과 절차}

본 연구에서는 학사경고 발생 원인과 대학학습에 가장 어려움을 느끼는 부분에 대한 분석을 통하여 학사경고자 대상 자기주도학습능력 증진 프로그램을 구성하였다. 즉 학사 경고 원인분석을 통해 밝혀진 바와 같이, 자기주도학습을 위한 동기부여, 시간관리, 노트 필기, 보고서 작성, 암기와 기억하기 등의 학습전략을 통해 대학학습에 도움을 줄 수 있 는 내용으로 영역을 구분하여 구성하였다.

대학생 학사경고자를 위한 자기주도적 학습능력 증진 프로그램은 50 분씩, 총 5 회기에 걸쳐 진행되었다. 기존에 운영하는 학사경고자 프로그램의 문제점을 파악하여 프로그램 운영 성과를 높이기 위한 방법들이 동원되었다. 학사경고자 학생들의 자발적인 참여가 중요함에 따라 프로그램을 신청 한 학생 중에서 프로그램에 빠짐없이 참석할 의사와 적 극적으로 참여할 것을 서면으로 약속받았다. 프로그램 오리엔테이션을 통해 프로그램에 대한 전반적인 안내, 프로그램 참여목적, 기대사항, 요구사항 등을 개별적으로 정하도록 하였다. 이러한 요구사항을 반영하여 구성한 프로그램의 구체적인 내용은 다음의 [표 3] 와 같다.

[표 3] 학사경고자 대상 자기주도학습능력 프로그램의 내용

[Table 3] Contents of Self-directed Learning Ability Improvement Program for Students on Academic Probation 


\begin{tabular}{|c|c|}
\hline 회기 & 프로그램 세부 내용 \\
\hline 1 차 & $\begin{array}{c}\text { 학습전략 I } \\
\text { 나의 학습스타일 분석(MLST 검사 실시),자신의 문제점 파악하기, 맞춤형 학습전략 점검 }\end{array}$ \\
\hline 2차 & $\begin{array}{c}\text { 학습전략 II } \\
\text { 자기주도학습을 위한 동기부여 전략법, 외재적 동기와 내재적 동기 부여 } \\
\text { 학습동기 부여. 학습목표 설정 }\end{array}$ \\
\hline 3 차 & $\begin{array}{c}\text { 학습전략 III } \\
\text { 내 생활을 바꿔주는 효율적인 시간 관리법 } \\
\text { 미루는 습관 바꾸기, }\end{array}$ \\
\hline 4차 & $\begin{array}{c}\text { 학습전략 IV } \\
\text { 만점받는 노트필기 전략, 보고서 작성법 } \\
\text { 점수높이는 답안지 작성법 }\end{array}$ \\
\hline 5 차 & $\begin{array}{c}\text { 학습전략 } \mathrm{V} \\
\mathrm{A}+\text { 학점을 위한 암기와 기억하기, 집중력 강화법 } \\
\text { 조별 수업 및 토론 방법 }\end{array}$ \\
\hline
\end{tabular}

\section{3 학사경고자 대상 자기주도학습능력 증진 프로그램의 결과 분석}

학사경고자를 위한 자기주도학습능력 증진 프로그램의 효과를 분석한 결과, 학사경고자 프로그램에 참여한 학생들의 자기주도학습능력이 향상되었다. 자기주도학습능력 검사의 사전/사후 결과를 비교해 보면 다음의 [표 4]와 같다.

‘학습계획'의 경우, 하위영역인 학습욕구와 목표설정, 학습자원파악의 사후점수는 $\mathrm{M}=3.05(\mathrm{SD}=.42), \mathrm{M}=3.12(\mathrm{SD}=.50), \mathrm{M}=3.22(\mathrm{SD}=.43)$ 으로 모두 통계적으로 유의미하였다. 자신 의 학습욕구를 파악하여 학습에 대한 목표를 세우고 자신이 가진 학습에 대한 자원을 파 악하는 데 효과가 있는 것으로 나타났다.

‘학습실행'의 경우도 하위영역인 자기관리능력과 학습전략선택, 지속성의 사후점수는 $\mathrm{M}=3.03(\mathrm{SD}=.55), \mathrm{M}=2.79(\mathrm{SD}=.56), \mathrm{M}=3.10(\mathrm{SD}=.49)$ 으로 모두 통계적으로 유의미하였다. 학습 에 관련하여 자기관리능력이 향상되었고 자신의 학습전략을 선택하고 학습을 지속하는데 프로그램이 효과적인 것으로 나타났다.

‘학습평가'의 경우도, 하위영역인 노력귀인, 자기성찰의 사후점수는 $\mathrm{M}=3.08(\mathrm{SD}=.47)$, $\mathrm{M}=3.13(\mathrm{SD}=.54)$ 로 모두 통계적으로 유의미하였다. 즉 학습에 대한 자신의 평가도 노력에 의한 결과이며 이를 통해 자기에 대한 성찰을 할 수 있게 되었다고 볼 수 있다.

결론적으로 학사경고자 대상 자기주도학습능력 증진 프로그램에 참여한 학사경고자의 자기주도학습능력이 전반적으로 향상되었다고 할 수 있다. 즉 학습계획, 학습실행, 학습 평가에 이르는 전반적인 학업과정을 학습자가 자기주도적으로 이끌어갈 수 있는 학습역 량을 강화시켰다. 자신에 학습욕구와 학습을 위한 지원에 대해 더 잘 파악하고 있었으며 기본적인 자기관리 능력과 자신에게 맞는 학습전략을 잘 선택할 수 있었다. 학습실행을 위한 계속하여 결과에 대한 노력을 인정하였다고 볼 수 있다. 
[표 4] 학사경고자 학생의 자기주도학습 증진 프로그램 사전/사후 결과 비교

[Table 4] ] Compare Results of Self-directed Learning Ability Improvement Program for Students on Academic Probation

\begin{tabular}{ccccccc}
\hline \multirow{2}{*}{ 자기주도적 학습능력 } & \multicolumn{2}{c}{ 사전 $\mathrm{M}(\mathrm{SD})$} & \multicolumn{2}{c}{ 사후 $\mathrm{M}(\mathrm{SD})$} & $\mathrm{t}$ \\
\hline & 학습욕구 & 2.73 & $(0.48)$ & 3.05 & $(0.42)$ & $-4.61^{* * * *}$ \\
\cline { 2 - 7 } 학습계획 & 목표설정 & 2.76 & $(0.49)$ & 3.12 & $(0.50)$ & $-3.78^{* *}$ \\
\cline { 2 - 7 } & 학습자원파악 & 2.87 & $(0.65)$ & 3.22 & $(0.43)$ & $-2.78^{*}$ \\
\hline \multirow{2}{*}{ 학습실행 } & 자기관리능력 & 2.72 & $(0.58)$ & 3.03 & $(0.55)$ & $-3.24^{* *}$ \\
\cline { 2 - 7 } & 학습전략선택 & 2.49 & $(0.63)$ & 2.79 & $(0.56)$ & $-2.71^{*}$ \\
\cline { 2 - 7 } & 지속성 & 2.79 & $(0.51)$ & 3.10 & $(0.49)$ & $-2.88^{* *}$ \\
\hline 낙습평가 귀인 & 2.65 & $(0.42)$ & 3.08 & $(0.47)$ & $-2.78^{*}$ \\
\cline { 2 - 7 } & 자기성찰 & 2.52 & $(0.43)$ & 3.13 & $(0.54)$ & $-3.14^{* *}$ \\
\hline
\end{tabular}

\section{5. 결론 및 제언}

\section{1 결론}

본 연구에서는 학사경고자가 주도적으로 학사경고를 탈출하고 성공적인 대학학습에 임 할 수 있도록 학사경고자 원인분석을 통한 자기주도학습능력 증진 프로그램을 운영하고 그 효과성을 검증하였다. 연구의 결과는 다음과 같다.

첫째, 학사경고원인분석 결과, 학사경고를 받은 근본적인 원인으로는 비효과적 학습방 법, 학습동기 및 의지부족, 전공이수 어려움, 심리 및 정서적 문제, 다른 대학 입시준비 및 취업, 가정형편, 건강 문제 순으로 나타났다. 대학학습에 가장 어려움을 느끼는 부분 으로는 학습전략 부족, 시간 관리, 조별 수업 및 토론, 노트 필기, 전공기초, 보고서 작성 순으로 나타났다.

둘째, 대학생 학사경고자를 위한 자기주도학습능력 증진 프로그램에 참여한 학사경고자 학생들의 자기주도학습능력이 전반적으로 향상되었다. 학습계획, 학습실행, 학습평가에 이르는 전반적인 학업과정을 학습자가 자발적으로 이끌어갈 수 있는 역량을 강화시켰다 고 할 수 있다. 자신의 학습에 대한 계획을 세우고 자신의 학습욕구와 학습을 위한 지원 에 대해 파악하는 능력이 향상되었다. 기본적인 자기관리 능력과 자신에게 맞는 학습전 략을 잘 선택할 수 있었으며 지속적으로 학습을 실행하는 능력도 향상되었다. 자신의 학 습에 대하여 노력에 기인한 것이며 자신에 대해 성찰을 하는 대한 전반적인 학습평가능 력도 향상되었다.

\section{2 제언}

본 연구의 결과를 토대로 학사경고자에 대한 대학 차원의 지원에 대해 구체적인 제언 을 해보면 다음과 같다.

첫째, 학사경고를 받는 원인을 분석해 본 결과, 학사경고는 학사경고자의 학습적인 문 
제로 발생하기도 하지만 개개인의 다양한 문제들로부터 발생한다. 가정적인 문제, 심리적 인 문제, 건강문제, 환경적인 문제 등등 개인적인 문제가 깊숙이 관여되어 있다. 따라서 학사경고자의 학사경고탈출을 도와주고 학업적인 성취를 높이기 위해서는 학사경고자의 다양한 개인적인 문제들을 적극적으로 해결해 줄 필요가 있다. 대학생들의 학업성취에 대한 전공 지도교수의 지속적인 관심이 필요하며 학교에 잘 적응하는지, 혹시 낙오되지 않는지 학교 차원에서 밀착하여 살펴보아야 한다.

둘째, 학사경고자의 학사경고 극복을 위하여는 학사경고자의 학습동기 강화가 필요하 다. 이를 고려하여 학사경고자 프로그램을 구성하여야 한다. 프로그램에는 삶의 목표 정 하기, 학업목표 정하기, 목표달성을 위한 전략 세우기, 전략에 따라 행동하기 등 학습동 기를 유발할 수 있는 다양한 동기유발 방법이 동원되어야 한다.

셋째, 학사경고자 발생 원인이 다양하므로 이와 관련된 다양한 프로그램을 운영할 필요 가 있다. 자기주도적인 학습능력 향상 프로그램, 자아존중감 향상 프로그램, 자기효능감 향상 프로그램, 진로 집단상담프로그램. 학업 미루기 감소 프로그램, 학습전략 시리즈 프 로그램, 시간관리 전략 프로그램, 보고서 작성 프로그램, 레포트 작성 프로그램, 집중력 향상 프로그램 등 다양한 주제로 운영되어야 한다.

넷째, 학사경고자 전반적인 관리는 학과와 교무처를 중심으로 이루어지되 학업적인 지 원은 교수학습지원센터에서, 심리적인 지원은 학생 상담센터나 심리 상담센터에서 지원 하여야 한다. 학사경고 원인 분석을 개인별로 실시하여 심리적인 부분에서의 지원은 심 리상담센터에서 이루어져야 하고 학습적인 부분에서는 교수학습지원센터에서 이루어져야 한다. 학과전공 교수와 교무처가 유기적으로 협력하여 학사경고자에 대한 체계적인 관리 가 이루어져 학사경고자가 발생하지 않도록 선제적으로 대응해야 한다.

다섯 번째, 학사경고자를 위한 프로그램은 단기성 프로그램 보다는 지속성을 가진 프로 그램으로 운영하여야 한다. 학사경고자가 일단 발생하면 학사경고자를 위한 직후 프로그 램의 운영도 중요하지만 프로그램 이수 후 학사경고 탈출 여부나 지속적인 성적점검을 통해 학사경고자가 지속적으로 학업에 어려움이 없는지 추후 관리가 필요하다

여섯 번째, 학사경고자를 위한 프로그램의 효과성을 높이기 위해서는 학사경고자들의 다양한 프로그램 참여 유인책을 동원할 필요가 있다. 프로그램에 참여하는 학생들의 기 대사항, 요구사항 등 학생들의 의견을 반영한 프로그램 개발은 학사경고자들의 프로그램 참여를 높이는데 기여할 것으로 보인다. 특히 학사경고자를 위한 프로그램 이수 후 성적 장학금 지급이나 학점인정, 교과목 이수 등 학생들의 자발적 참여를 이끌어내는 방법을 동원하여 학생들의 참여를 유도하는 것이 필요하다. 이는 학사경고자들의 대학 학습의 성공, 학사경고 탈출, 학사경고 재발 방지, 중도탈락 예방까지도 기대해볼 수 있다

일곱 번째, 학사경고자에 대한 학습지원은 전문연구원과의 $1: 1$ 학습 상담이나 학습 컨 설팅을 통한 맞춤형 학습지원이 더 바람직하다. 학사경고자 학생들과의 $1: 1$ 학습 상담 및 학습 컨설팅 지원은 동료나 멘토로부터 받는 정서적 지원과 심리적 안정에 해당하는 것으로 학사경고자들의 학업 성취 및 성적 향상에 긍정적인 효과를 줄 수 있다.

마지막으로 학사경고자 프로그램은 예방 차원에서 운영되어야 한다. 교수학습지원센터 전문연구원과의 학습 상담, 학과 지도교수, 학과 선배들과의 멘토링 프로그램을 활용하는 것도 필요하다. 학사경고는 학업 부진이 일어났을 때부터 체계적으로 관리할 필요가 있 는데 이를 위해서는 학사경고 예측모형을 개발하는 것이 먼저 필요하다. 학사경고자뿐 만 아니라 학업이 부진한 학생들에 대한 예측은 성공적인 대학학습을 위해 필요하다고 볼 수 있다. 


\section{References}

[1] IrangLim, The Effects of Academic Self-Efficacy and Cognitive Strategy on the Academic Adaptation of Underachieving College Students: Moderated Mediation Effect of Social Support, Forum for Youth Culture, (2019), No.60, pp.117-146.

[2] M. S. Knowles, Self-diredted learning: A Guide for learners and teacher, USA Chicago: IL Follet Publishing Company, (1975)

[3] Na-mi Kim, Hyoe-won Kim, The Verification of Effectiveness of a Self-directed Learning Program through a PeerMentoring System of Colleg Students on Academic Probation, Journal of Learner-Centered Curriculum and Instruction, (2015), Vol.15, No.12, pp.875-900.

[4] M. A. Hanger, J. Goldenson, M. Weinberg, A. Schmitz-Sciborskim, R. Monzon, The bounce back retention program; One year follow-up study, Journal of College Student Retention, (2011), Vol.13, No.2, pp.205-227.

[5] Jong-Do Kim, College Students on Academic Probation interviews and academic achievement, Korea Entertainment Industry Association,(2016), Vol.10, No.3, pp.253-265.

[6] Bo-ra Jun, Sung-Hye Kang, So-jung Yoon, Academic characteristics of college students and the effect of collective learning consulting, Learner-centered curriculum education research, (2015), Vo.15. No.9, pp.137-160.

[7] Yong-Jin Lee, Hyun-jung Yang, Sung-Hee Cho, Exploring the nature of College Students on Academic Probation and the need for educational intervention, Education Methodology Society, (2018), Vol.29, No.1, pp.161-184.

[8] M. H. Yang, Learning Problems and Diagnosis of University Students, Proceeding of Counseling Council for University Student Summer Conference, Counseling Council for University Student, pp.139-153, (2014)

[9] Joo-myung Chun, Min-hyuk Whan, Myung-sook Han, Lim YeongjinAcademic Counseling for College students on Academic Probation, Journal of Student Counseling, (2014), Vol.22, pp.163-181.

[10] Na-mi Kim, Hyoe-won Kim, Wan-sung Bak, Effects of a Resilience Improvement Program Applying a PeerMentoring System on College Students on Academic Probation, The Journal of Yeolin Education, (2014), Vol.22, No.1, pp.391-412.

[11] Young-A Joo, Hee-jin Jung, Sun-hee Whang, Young-hye Kim, Study on the Effects of a Group Counseling Program to Enhance Self-Determination and Stress Coping Strategies for the Academically Underachieving College Students, Journal of Learner-Centered Curriculum and Instruction, (2013), Vol.13, No.2, pp.85-115.

[12] J. R. Lee, M. K. Cho, A Qualitative Study on the Experience of Recurrent Academic Probation in University, Korean Journal of College Counseling, (2016), Vol.22, No.1, pp.25-45.

[13] Suk-Jae Lee, Yoo-Kyung Chang, Hun-Nam Lee, Kwang-Yup Park, A Study on the Development of Life-Skills: Communication, Problem Solving, and Self-Directed Learning, Korea: KEDI, (2003) 